\title{
HPLC-DAD-ESI+-MS PHYTOCHEMICAL PROFILES OF SEVERAL ROSMARINUS OFFICINALIS ACCESSIONS FROM SPAIN AS INFLUENCED BY DIFFERENT ENVIRONMENTAL STRESS CONDITIONS
}

\section{MONICA BOSCAIUa, OSCAR VICENTE ${ }^{b, e}$, INMACULADA BAUTISTA ${ }^{c}$, FLORICUTA RANGA ${ }^{\mathrm{d}}$, CARMEN SOCACIU ${ }^{\mathrm{d}, *}$}

\begin{abstract}
Rosemary, a native Mediterranean plant is a well-known source of phytochemicals with antioxidant activity attributed mainly to diterpenoids and flavonoids. The aim of the study was to establish an accurate evaluation of the rosemary metabolite profiles from several accessions under changing environmental conditions (water stress and soil salinity) comparing two sampling seasons (summer vs. spring) from four different habitats in Eastern Spain. The methodology was based on the identification and the quantitative evaluation of phytochemicals (phenolic acid derivatives, flavonoids, diterpenes and triterpenes) by HPLC coupled with diode-array detection and electrospray ionization mass spectrometry (ESI+-MS). Phytochemical profiles were statistically compared by factorial ANOVA, cluster analysis, principal component analysis and univariate analysis (Pearson correlations), that allowed the discrimination between the extract composition in correlation to their habitat and stress conditions. Out of twenty-three compounds identified, the major ones were represented by diterpenoids (carnosic acid, carnosol and oxidized metabolites rosmanol, epirosmanol, rosmadial, rosmanol methyl ether) and flavonoids, which showed significant metabolic regulation induced by water stress. The main conclusion of the work is that the diterpene derivatives and their oxidized metabolites may be considered as optimal biomarkers of the environmental stress in Rosmarinus officinalis.
\end{abstract}

Keywords: Rosmarinus officinalis; environmental stress; high performance liquid chromatography \& mass spectrometry; metabolomic profile

a Universitat Politècnica de València, Instituto de Biología Molecular y Celular de Plantas (UPV-CSIC), Camino de Vera s/n, 46022 Valencia, Spain

b Universitat Politècnica de València, Instituto Agroforestal Mediterráneo, Camino de Vera s/n, 46022 Valencia, Spain

c Universitat Politècnica de València, ReForest, Instituto Ingeniería del Agua y Medio Ambiente, Camino de Vera s/n, 46022 Valencia, Spain

d University of Agricultural Sciences and Veterinary Medicine. 3-5 Manastur Street. 400372 Cluj-Napoca. Romania

e Universitat Politècnicva de València, Instituto de Conservación y Mejora de la Agrodiversidad Valenciana (COMAV), Camino de Vera s/n, 46022 Valencia, Spain

*Corresponding author: carmen.socaciu@usamvcluj.ro 
MONICA BOSCAIU, OSCAR VICENTE, INMACULADA BAUTISTA, FLORICUTA RANGA, CARMEN SOCACIU

Abbreviation list
DAD - Diode Array Detection
GC- Gas-chromatgraphy
LC- Liquid Chromatography
HPLC - High Performance Liquid Chromatography
$\mathrm{ESI}^{+}-\mathrm{MS}$ - Electrospray ionization mass spectrometry
CA - cluster analysis
PCA - principal component analysis
MS - Mass spectrometry
ROS - Reactive Oxygen Species
AsA-GSH - Ascorbate- glutathion

\section{INTRODUCTION}

Rosemary (Rosmarinus officinalis L., Lamiaceae family) is a woody herb that grows wild in the Mediterranean region, but is also largely cultivated in many areas worldwide as a tasty culinary spice. It has also well-known medicinal uses, such as antimicrobial [1-3] or neuroprotective [4,5]. Rosemary's high medicinal interest is mainly due to its antioxidant potential brought by its high contents in terpenoids and phenolic derivatives [6-9]. Numerous scientific studies were performed on the chemical composition of rosemary. Advanced techniques, such as high performance liquid chromatography (HPLC) or gas chromatography (GC) coupled with diode array (DAD) or mass spectrometry (MS) detection, are currently used to separate and identify bioactive metabolites in rosemary extracts [10-12]. The major compounds were represented by phenolic diterpenoids (e.g. carnosic acid and carnosol, rosmanol), flavonoids (rosmarinic acid and luteolin derivatives, genkwanin or homoplantaginin) or pentacyclic triterpenoids (oleanolic, betulinic and ursolic acids) [13-16] besides monoterpenes (cineole, camphor and $\alpha$-pinene). Ultrasound or microwave-assisted procedures have improved the extraction efficiency of rosemary components [15, 17,18]. An HPLC/DAD/MS study [19] showed that drying temperature, storage conditions and extraction procedures can affect the chemical composition of leaf extracts, especially the high antioxidant derivatives e.g. rosmarinic acid and carnosic acid [20, 21].

The phytochemical profile of rosemary was related to its phenological stage [22], geographic location [18, 23], seasonal variation [7] and abiotic stresses, such as drought [24], salinity [25] or photoxidation [26]. Under stressful conditions, including irrigation with effluents that contain high levels of salts and heavy metals, rosemary accumulates reactive oxygen species, which leads to the activation of antioxidant defence mechanisms [13]. Using accessions of rosemary, grown in different field trials and sites in Greece, it was shown that the phenolic chemical profile and the antioxidant behaviour of carnosic acid were affected by stress [27]. 
Environmental stress has a strong influence on the biosynthesis of bioactive compounds, by generation in excess of ROS, a group of free radicals, reactive molecules and ions derived from oxygen. ROS are normal by-products of cellular metabolisms but under conditions of abiotic and biotic stress the balance between their formation and scavenging is lost, and levels of ROS increase. As they are highly reactive and toxic, when in excess, they produce oxidative stress, affecting cells' physiology and eventually leading to cellular death. To mitigate oxidative stress, organisms activate their enzymatic and chemic or non-enzymatic defence mechanisms. In plants, the first category is represented by several enzymes, mainly by those involved in the ascorbateglutathione cycle (AsA-GSH) in chloroplasts, cytosol, mitochondria, apoplast, and peroxisomes. Non-enzymatic antioxidants, include diverse chemical compounds, such as ascorbic acid and E vitamin, carotenoids, reduced glutathione or phenolic compounds, especially the subclass of flavonoids [28]. The antioxidant enzymes represent 'the first line of defence against ROS', but under severe stress their activity may be insufficient for maintaining the ROS homeostasis. At this stage, the biosynthesis of secondary ROS scavenging systems (non-enzymatic compounds) is triggered [29]. As such, plants naturally growing in harsh environmental situations, should have efficient mechanisms to reduce the oxidative damage associated with situations of drought, increased salinity or other types of environmental stress. The role of phenolic compounds in plants is well-known [30, 31]. Out of the wide array of their biological functions, phenolics and especially flavonoids, participate in plant responses to practically all types of abiotic stress: UV radiation, intense light, extreme temperatures, mineral nutrient imbalance, anoxia, ozone exposure, drought, salinity, heavy metals and herbicides [30, 31-35].

In this study, we have analysed samples of rosemary collected in the wild, from different types of environments in South East of Spain. All habitats selected suffer the rigor of Mediterranean climate characterized by dry summers; the combination of drought, high temperatures, risk of salinity and high solar radiation induces a multiple stress, and plants tend to reduce their vegetative activity during this time. There are several well-known strategies developed by Mediterranean plants to with stand the restrictions of the summer stress, such as the syndrome of Sclerophyllous leaves or reduction of vegetative activity by the loss of leaves in summer. On the other hand, apart from these anatomic and physiologic adaptations, biochemical responses are triggered, such as osmotic adjustment or activation of antioxidant systems, both chemic and enzymatic, as response to the oxidative stress generated by the activation of ROS, with direct deleterious effects by oxidation of proteins, membrane lipids and nucleic acids. Previously, the content of total phenolics and flavonoids has been determined by spectrophotometric methods in different 
plant species, including $R$. officinalis, from these Mediterranean habitats, and a significantly positive correlation between the level of these compounds and soil water deficit was established [36].

The present study aimed to establish phytochemical profiles of four Rosmarinus officinalis accessions, as influenced by different environmental growth conditions (two sampling seasons: in spring under favourable climatic conditions vs summer dry conditions) in Spain. The hypothesis of work is that the concentrations of main antioxidants will be correlated with environmental parameters, especially those related to the water deficit. The rosemary extracts were analysed by a combined, simultaneous HPLC-DAD and LC$\mathrm{ESI}^{+}-\mathrm{MS}$ procedure, in order to evaluate the phytochemicals' fingerprinting and the quantitative analysis of main compounds, followed by statistical analysis. The impact of the environmental stress was established by focusing on the variations of phenolic compounds and terpenoids.

\section{RESULTS AND DISCUSSION}

\section{Phytochemicals profile and identification by LC-ESI + -MS}

Fig. 1 shows the general fingerprint of thirty-six superposed LC-ESI+-MS chromatograms (peak area versus retention time) of rosemary extracts from the sampling groups. Based on their retention times, $\mathrm{m} / \mathrm{z}$ values and main fragments twenty-three compounds were separated and tentatively assigned.

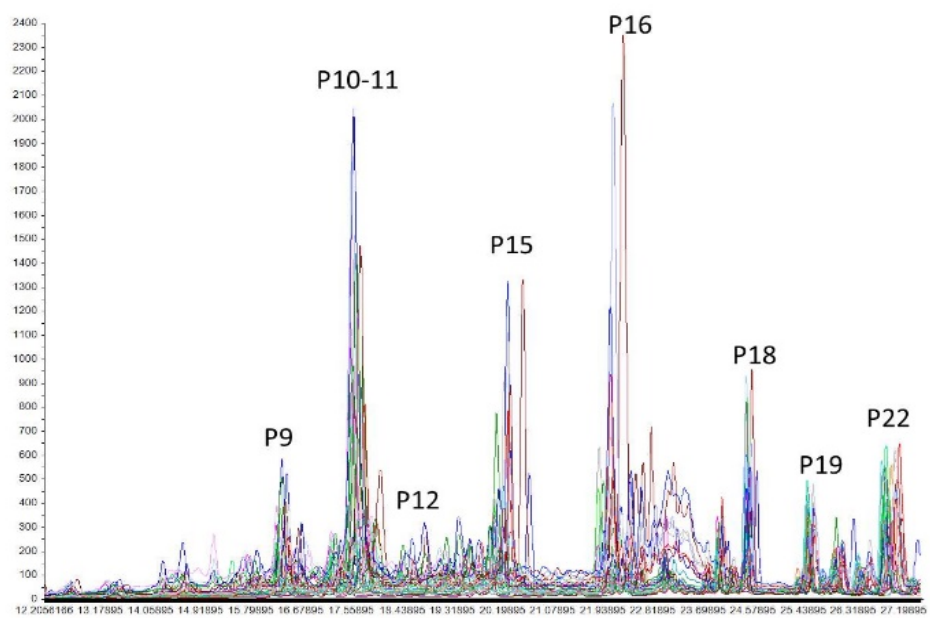

Figure 1. A general view of thirty six superposed LC-ESI'-MS chromatograms (peak area versus retention time) obtained from eight sampling groups. The major compounds were marked as P9, P10-11, P12, P15, P16, P18, P19 and P22. 
Table 1 includes the retention times $\left(t_{R}\right)$, the specific $m / z[M+H]^{+}$values, the main fragments derived from the MS analysis, and tentative identification, as compared with the literature data and data bases (Phenol Explorer, KEGG). Three categories of phytochemicals were identified: (1) diterpenoid ethers and other conjugates, (2) phenolic acid derivatives, and (3) flavonoids (luteolin derivatives).

Table 1. LC-ESI+ ${ }^{+} M S$ data provided for rosemary extracts: retention time $t_{R}(\mathrm{~min})$ ), $\mathrm{m} / \mathrm{z}$ values used for ESI (+)MS identification, the main fragments and the identified compounds, in agreement with international data bases.

\begin{tabular}{|c|c|c|c|c|}
\hline Name & $t_{R}(\min )$ & $\frac{\mathrm{m} / \mathbf{z}}{[\mathrm{M}+\mathrm{H}]^{+}}$ & $\begin{array}{c}\text { Main } \\
\text { MS } \\
\text { Fragments }\end{array}$ & Tentative identification \\
\hline $\mathrm{P} 1$ & 2.91 & 199.0510 & $181 ; 137$ & Syringic acid \\
\hline $\mathrm{P} 2$ & 3.90 & 193.0553 & $129 ; 95$ & p-Coumaric acid ethyl ester \\
\hline P3 & 12.02 & 465.0884 & $303 ; 287$ & Quercetin 3-O-glucoside \\
\hline $\mathrm{P} 4$ & 12.64 & 523.1320 & $361 ; 325$ & Rosmarinic acid 3-O-glucoside \\
\hline P5 & 13.49 & 479.1130 & $464 ; 317 ; 302$ & $\begin{array}{l}\text { Nepetrin (6-methoxy-luteolin 7-O- } \\
\text { glucoside) }\end{array}$ \\
\hline P6 & 14.29 & 611.1535 & 303 & $\begin{array}{l}\text { Hesperidin (Luteolin 7,3'- } \\
\text { diglucoside) }\end{array}$ \\
\hline P7 & 14.65 & 463.1089 & $285 ; 163$ & Homoplantaginin \\
\hline P8 & 15.96 & 463.0798 & 287 & Luteolin3'-glucuronide \\
\hline P9 & 16.40 & 361.0772 & $199 ; 181 ; 163 ; 137$ & Rosmarinic acid \\
\hline P10 & 17.33 & 505.0905 & $401 ; 287$ & $\begin{array}{l}\text { Luteolin 3'-(3"-acetylglucuronide) } \\
\text { Isomer I }\end{array}$ \\
\hline P11 & 17.74 & 505.0905 & $445 ; 287$ & $\begin{array}{l}\text { Luteolin 3'-(4"-acetylglucuronide) } \\
\text { Isomer II }\end{array}$ \\
\hline $\mathrm{P} 12$ & 18.58 & 347.1707 & $303 ; 285$ & Rosmanol \\
\hline P13 & 19.36 & 347.1707 & 285 & Epirosmanol ( isomer 1) \\
\hline P14 & 19.73 & 285.0611 & 270 & Genkwanin \\
\hline $\mathrm{P} 15$ & 20.24 & 331.1863 & 287 & Carnosol \\
\hline P16 & 22.06 & 303.0427 & $229 ; 153$ & Quercetin \\
\hline $\mathrm{P} 17$ & 24.03 & 317.1965 & 287 & Rosmaridiphenol \\
\hline P18 & 24.54 & 345.1707 & $317 ; 301 ; 285$ & Rosmadial \\
\hline P19 & 25.66 & 473.1869 & 457 & Benthamic acid \\
\hline $\mathrm{P} 20$ & 26.15 & 361.1966 & $333 ; 287$ & Rosmanol methyl ether \\
\hline $\mathrm{P} 21$ & 26.63 & 347.1863 & $333 ; 287$ & 12-Methoxy carnosic acid \\
\hline $\mathrm{P} 22$ & 27.12 & 333.1864 & 287 & Carnosic acid \\
\hline P23 & 27.59 & 455.1867 & - & Micromeric acid \\
\hline
\end{tabular}


Nine compounds were selected as being major, based on the chromatogram peak intensity higher than 200 and signal/noise ratio of minimum 3 (Fig. 1). These compounds were tentatively identified as follows, P9 (rosmarinic acid), P10 and P11 (two isomers of luteolin acetyl glucuronide), P12 (rosmanol), P15 (carnosol), P16 (quercetin), P18 (rosmadial), P19 (benthamic acid) and P22 (carnosic acid) (Table 1). Fig. 2 shows the chemical structures of the main compounds.

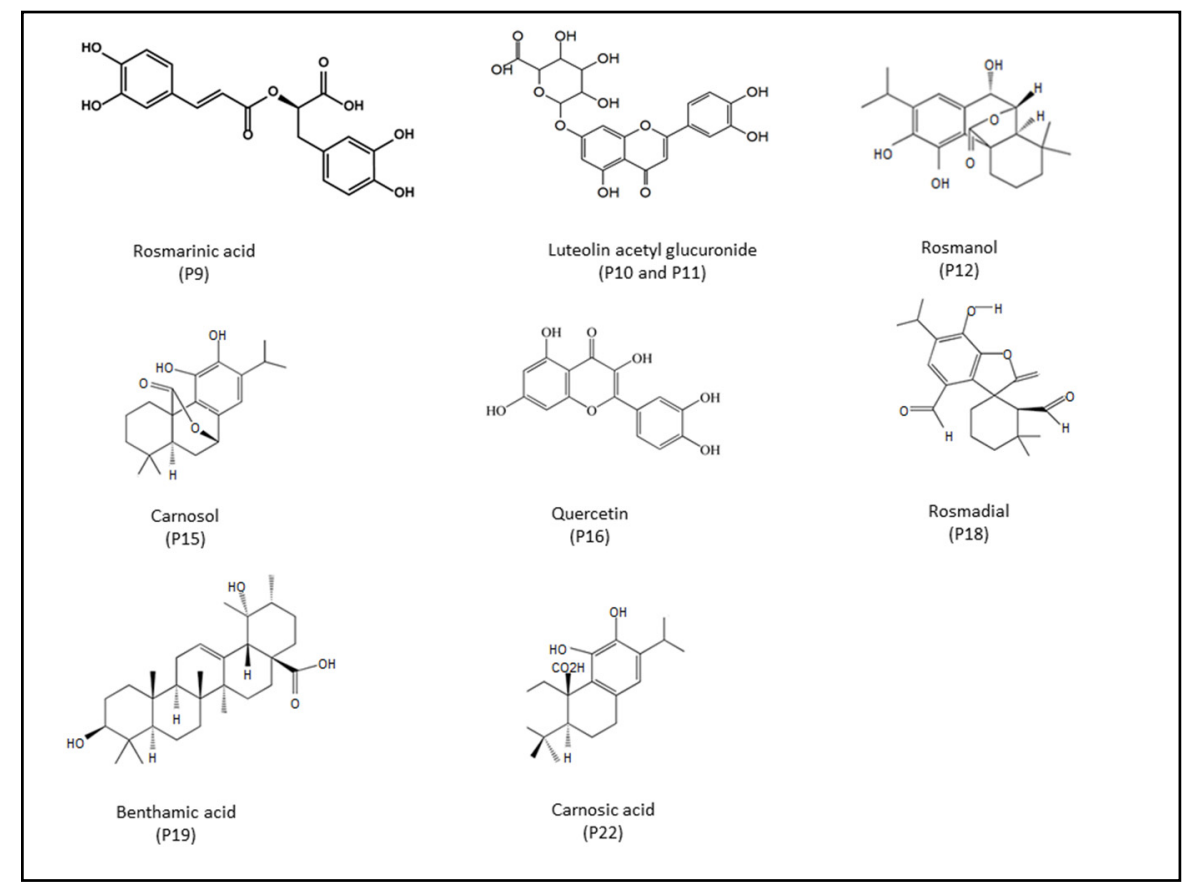

Figure 2. Chemical structure of the major compounds identified in the rosemary samples.

The first major class of compounds from diterpene family were carnosic acid (P22, $\mathrm{m} / \mathrm{z}=333.1864)$, carnosol ( $\mathrm{P} 15, \mathrm{~m} / \mathrm{z}=331.1863)$, methylcarnosate ( $P 21, \mathrm{~m} / \mathrm{z}=347.1863)$. Rosmanol ( $\mathrm{P} 12, \mathrm{~m} / \mathrm{z} 347.1707)$ and its isomer epirosmanol (P13, $m / z=347.1707$ ) were formed by oxidative degradation of carnosic acid. Rosmaridiphenol (P17, $\mathrm{m} / \mathrm{z}$ 317.1965, with a fragment of 287), rosmadial (P18, $\mathrm{m} / \mathrm{z} 345.1707)$ and rosmanol methylether (P20, $\mathrm{m} / \mathrm{z}$ 361.1965) were also identified. All these compounds have been previously reported also by other authors [37]. In addition, some minor triterpenes, namely benthamic (P19, $\mathrm{m} / \mathrm{z}$ 473.1869) and micromeric acid (P23, $\mathrm{m} / \mathrm{z} 455.1867$ ) were also detected. 
The phenolic acid derivatives were represented by rosmarinic acid (P9, $\mathrm{m} / \mathrm{z}$ 361.0772), a caffeic acid ester of salvianic acid $A$ and rosmarinic acid 3-O-glucoside (P4, m/z 523.1320S). Syringic acid (P1) and p-coumaric ethyl ester (P2), were also identified, but only as minor components.

Flavonoids such as glucuronic acid derivatives of luteolin, represented by luteolin 3'O-(3"O-acetyl) $\beta$-D-glucuronide (P10-isomer I-, $\mathrm{m} / \mathrm{z}$ 505.0905) and luteolin 3'O-(4"O-acetyl) $\beta$-D-glucuronide (P11-isomer II, $\mathrm{m} / \mathrm{z}$ 505.0905) were also identified. The MS analysis revealed their specific fragmentation and discrimination by fragments of $\mathrm{m} / \mathrm{z} 410$ and 445, respectively. Other minor luteolin derivatives were identified, e.g. nepetrin ( $P 5, m / z$ 479.1130), hesperidin (P6, $\mathrm{m} / \mathrm{z}$ 611.1535), homoplantagin (P7, $\mathrm{m} / \mathrm{z}$ 463.0798), luteolin 3'-glucuronide (P8, $\mathrm{m} / \mathrm{z}$ 463.0798) and genkwanin ( $\mathrm{P} 14, \mathrm{~m} / \mathrm{z} 285$.0611). Flavonols were also identified, including quercetin (P16, $\mathrm{m} / \mathrm{z} 303.0427)$ and quercetin 3-O-glucoside (P3, $m / z$ 465.0884), in agreement with other reported data [14, 17].

The major fragment, with $m / z=287$, corresponded to glucuronic acid loss, as indicated by previous data found in the literature and databases. For nepetrin (P5) and quercetin 3-O-glucoside (P3), the fragment ions with $\mathrm{m} / \mathrm{z} 317$ and 302 were assigned to fragments arising from glucose loss. Similarly, hesperidin (P6) presented a major fragment ion at $\mathrm{m} / \mathrm{z} 302$ due to rutinoside loss.

\section{Quantitative analysis by HPLC-DAD}

Based on the preliminary profile evaluations, the flavonoid derivatives (P10, P11 and P16) were the major components of extracts, therefore, we used rutin as a representative flavonoid for the calibration curve. The mean concentrations of all 23 compounds were calculated from the calibration curve equation and expressed as micrograms rutin equivalent/g dry leaf.

Table 2 presents the mean values and standard deviations $(x \pm S D)$ of the 23 compounds, as determined by HPLC-DAD, after calibration with rutin. A large variability was observed between these compositions, inside an accession group but especially between the different accession groups, as can be seen for luteolin glucuronide isomers (P10 and P11), rosmarinic acid (P9), carnosic acid derivatives (P15 and P22), rosmanol (P12) and rosmadial (P18), quercetin (P16), and benthamic acid (P19).

Although some of the compounds show significant differences between areas; P7 homoplantagin and P23 micromeric acid, the greatest differences can be found in samples from different seasons. The phenolic acids rosmarinic (P9) and it derivate P4 rosmarinic acid 3-O-glucoside increase significantly in summer. Most of the flavonoids also increase significantly in summer time: P5 Nepetrin (6-methoxy-luteolin 7-O-glucoside), P6 Hesperidin (Luteolin 7,3'diglucoside), P8 Luteolin3'-glucuronide, P10 and P11 Isomers I and II of Luteolin 3'-(3"-acetylglucuronide), P14 Genkwanin and P16 Quercetin. 
Table 2- Mean values \pm standard deviation of the quantified phytochemicals (P1 to P23) in the different areas (A) and sampling date (B- summer and spring).

Significant differences by multiple comparison (Two way anova) at $P<0.05$ :

${ }^{*},{ }^{* *}$. ${ }^{* * *}$, significant at $\mathrm{P}<0.05,0.01$ and 0.001 respectively.

\begin{tabular}{|c|c|c|c|c|c|c|c|c|c|c|}
\hline \multirow{3}{*}{$\begin{array}{l}\text { Plot/ } \\
\text { season } \\
\text { P1 }\end{array}$} & \multicolumn{2}{|c|}{ Gypsum top } & \multicolumn{2}{|c|}{ Gypsum bottom } & \multicolumn{2}{|c|}{ Semiarid } & \multicolumn{2}{|l|}{ Dune } & \multirow[t]{2}{*}{ A. } & \multirow[t]{2}{*}{ B. } \\
\hline & Spring & Summer & Spring & Summer & Spring & Summer & Spring & Summer & & \\
\hline & 100 & 95 & 61 & 161 & 49 & 89 & 104 & 108 & NS & NS \\
\hline & \pm 12 & \pm 60 & \pm 76 & \pm 35 & \pm 42 & \pm 49 & \pm 48 & \pm 60 & & \\
\hline \multirow[t]{2}{*}{ P2 } & 117 & 152 & 115 & 143 & 139 & 107 & 131 & 120 & NS & NS \\
\hline & \pm 54 & \pm 18 & \pm 66 & \pm 20 & \pm 21 & \pm 64 & \pm 19 & \pm 69 & & \\
\hline \multirow[t]{2}{*}{ P3 } & 66 & 274 & 301 & 201 & 65 & 147 & 173 & 298 & NS & NS \\
\hline & \pm 53 & \pm 115 & \pm 69 & \pm 59 & \pm 32 & \pm 93 & \pm 65 & \pm 65 & & \\
\hline \multirow[t]{2}{*}{ P4 } & 83 & 303 & 119 & 298 & 77 & 304 & 178 & 219 & NS & ** \\
\hline & \pm 42 & \pm 243 & \pm 83 & \pm 95 & \pm 72 & \pm 56 & \pm 99 & \pm 96 & & \\
\hline \multirow[t]{2}{*}{ P5 } & 77 & 329 & 105 & 334 & 101 & 286 & 237 & 286 & NS & $* * *$ \\
\hline & \pm 36 & \pm 185 & \pm 55 & \pm 92 & \pm 43 & \pm 58 & \pm 92 & \pm 94 & & \\
\hline \multirow[t]{2}{*}{ P6 } & 84 & 378 & 70 & 432 & 79 & 168 & 328 & 388 & NS & $* *$ \\
\hline & \pm 40 & \pm 373 & \pm 21 & \pm 98 & \pm 54 & \pm 54 & \pm 99 & \pm 89 & & \\
\hline \multirow[t]{2}{*}{$\mathrm{P} 7$} & 62 & 275 & 450 & 478 & 149 & 562 & 608 & 873 & * & NS \\
\hline & \pm 12 & \pm 171 & \pm 97 & \pm 78 & \pm 86 & \pm 67 & \pm 98 & \pm 97 & & \\
\hline \multirow[t]{2}{*}{ P8 } & 164 & 723 & 731 & 948 & 417 & 749 & 549 & 672 & NS & * \\
\hline & \pm 87 & \pm 306 & \pm 76 & \pm 87 & \pm 78 & \pm 65 & \pm 76 & \pm 65 & & \\
\hline \multirow[t]{2}{*}{ P9 } & 165 & 1561 & 688 & 1391 & 516 & 1522 & 1565 & 1551 & NS & $* * *$ \\
\hline & \pm 54 & \pm 564 & \pm 76 & \pm 372 & \pm 68 & \pm 95 & \pm 78 & \pm 87 & & \\
\hline \multirow[t]{2}{*}{ P10 } & 464 & 1118 & 807 & 1159 & 716 & 1240 & 996 & 1759 & NS & * \\
\hline & \pm 24 & \pm 521 & \pm 369 & \pm 339 & \pm 95 & \pm 543 & \pm 294 & \pm 150 & & \\
\hline \multirow[t]{2}{*}{ P11 } & 331 & 4730 & 1865 & 4145 & 831 & 4870 & 3681 & 4695 & NS & ** \\
\hline & \pm 20 & \pm 337 & \pm 142 & \pm 165 & \pm 90 & \pm 297 & \pm 255 & \pm 514 & & \\
\hline \multirow{2}{*}{ P12 } & 399 & 1418 & 1048 & 849 & 725 & 1844 & 1141 & 349 & NS & NS \\
\hline & \pm 85 & \pm 102 & \pm 785 & \pm 691 & \pm 96 & \pm 120 & \pm 139 & \pm 219 & & \\
\hline \multirow[t]{2}{*}{ P13 } & 146 & 693 & 455 & 890 & 496 & 1040 & 875 & 1336 & * & $* *$ \\
\hline & \pm 15 & \pm 485 & \pm 203 & \pm 419 & \pm 25 & \pm 341 & \pm 350 & \pm 695 & & \\
\hline \multirow[t]{2}{*}{ P14 } & 182 & 936 & 374 & 1122 & 361 & 911 & 912 & 1330 & NS & $\star * *$ \\
\hline & \pm 17 & \pm 495 & \pm 191 & \pm 335 & \pm 22 & \pm 481 & \pm 488 & \pm 599 & & \\
\hline P15 & 989 & 2483 & 982 & 1971 & 988 & 2104 & 2424 & 2645 & NS & NS \\
\hline & \pm 90 & \pm 180 & \pm 44 & \pm 805 & \pm 92 & \pm 974 & \pm 111 & \pm 157 & & \\
\hline P16 & 258 & 3399 & 322 & 2178 & 728 & 3924 & 2171 & 1839 & NS & * \\
\hline & \pm 98 & \pm 392 & \pm 144 & \pm 722 & \pm 82 & \pm 401 & \pm 157 & \pm 226 & & \\
\hline P17 & 507 & 747 & 539 & 773 & 639 & 765 & 482 & 515 & NS & NS \\
\hline & \pm 64 & \pm 319 & \pm 72 & \pm 323 & \pm 73 & \pm 122 & \pm 192 & \pm 276 & & \\
\hline P18 & 956 & 2094 & 496 & 1475 & 890 & 2062 & 579 & 1573 & * & ** \\
\hline & \pm 82 & \pm 606 & \pm 140 & \pm 327 & \pm 20 & \pm 237 & \pm 243 & \pm 521 & & \\
\hline P19 & 998 & 727 & 1121 & 1042 & 985 & 1259 & 1072 & 785 & NS & NS \\
\hline & \pm 92 & \pm 311 & \pm 213 & \pm 321 & \pm 91 & \pm 147 & \pm 371 & \pm 76 & & \\
\hline P20 & 747 & 800 & 743 & 768 & 834 & 883 & 527 & 798 & NS & NS \\
\hline & \pm 87 & \pm 332 & \pm 96 & \pm 93 & \pm 94 & \pm 287 & \pm 76 & \pm 87 & & \\
\hline P21 & 821 & 492 & 584 & 800 & 73 & 718 & 449 & 667 & NS & NS \\
\hline & \pm 95 & \pm 301 & \pm 83 & \pm 95 & $7 \pm 94$ & \pm 115 & \pm 86 & \pm 89 & & \\
\hline P22 & 2296 & 2089 & 2854 & 1703 & 999 & 1551 & 1949 & 1799 & NS & * \\
\hline & \pm 427 & \pm 955 & \pm 343 & \pm 446 & \pm 93 & \pm 464 & \pm 856 & \pm 345 & & \\
\hline P23 & 425 & 394 & 437 & 566 & 512 & 635 & 397 & 410 & * & NS \\
\hline & \pm 23 & \pm 177 & \pm 89 & \pm 83 & \pm 90 & \pm 236 & \pm 32 & \pm 20 & & \\
\hline
\end{tabular}


The water stress (summer drought) induced a significant increase of diterpenoids rosmadial (P18) in all plots, whereas carnosic acid (P22) had higher content in spring. Differences in compounds are more significant in the two plots subjected to greater water stress, that are one from the gypsum area, on top of the hill and the semiarid area.

In the dune area, these differences were not as significant. This pattern can be explained by a constant environmental stress in this habitat, independent on the season: similar salinity and low water retention of the sandy substrate.

When comparing the two plots in the gypsum area, the mean concentrations of these compounds are related to water stress. In spring, due to humidity and rains, the site at the bottom of the hill became more stressful for plants because the gypsum soil concentration (salt stress) was higher than at the top. Generally, non-significant effects of altitude were detected in summer time.

The concentrations of minor components ranged between 90 and 130 micrograms rutin eq./g dry leaf. Such components were represented by rosmarinic acid derivatives (P13, P17, P20), micromeric acid (P23), methoxycarnosate (P21) luteolin derivatives (P8, P14), glycosylated flavonoid derivatives (P3-P7) and phenolic acids (P1 and P2).

Comparing the concentrations of different phytochemical classes, the most significant differences were observed for flavonoids and rosmarinic acid derivatives, positively correlated with water stress.

Significant increases were noticed in summer compared with spring for flavonoid glycosides (P4-P6, P13, P17) in the gypsum zone and in the semiarid area but no differences were observed for triterpenes and diterpenes. The levels of the some compounds increased in summer in the dune sand, especially epirosmanol (P13) and genkwanin (P14). These data suggest that specific synthesis of flavonoids and terpenes, as well their oxidation is up-regulated by the environmental stress, in agreement with other data [38]. The most significant effects on rosemary metabolites from different accession groups studied here were mainly related to water stress (summer vs spring) and, to a lesser extent, to salt stress (sea vs gypsum).

The potent antioxidant properties of $R$. officinalis extract is attributed to its diterpene, carnosic acid, that under drought conditions scavenges free radical within the cloroplast giving highly oxidized diterpenes such as carnosol, rosmanol and isorosmanol $[7,13]$. The antioxidant protection mechanism by carnosic acid is especially relevant in rosemary $[13,26]$. In this context, our data reflected similar findings: not only an up-regulation of flavonoid synthesis is induced by water stress, but also a post-synthesis oxidation of carnosic acid to its metabolites (carnosol, methoxy carnosate). 
MONICA BOSCAIU, OSCAR VICENTE, INMACULADA BAUTISTA,

FLORICUTA RANGA, CARMEN SOCACIU

\section{Statistical correlations and significance of phytochemicals' modifications induced by environmental stress}

The Cluster analysis (CA) allowed the identification of the similarities and discriminations between the different accession groups of rosemary. The Euclidian distance among the accession groups shows good discriminations between the profiles of samples A1, B1, C1, D1 collected in summer (water stress - dry season) and samples D2, B2, A2, B2 collected in spring (humid season).

Table 3. Pearson correlation factors (R) and their significance (S), considering the differences between the mean values $(x \pm S D$ ) of phytochemicals' total concentrations found in accession groups. The significant correlations are bolded.

\begin{tabular}{|l|l|l|l|l|l|l|l|l|l|}
\hline & & A1 & B1 & A2 & B2 & C1 & C2 & D1 & D2 \\
\hline \multirow{2}{*}{ A1 } & R & 1 & $\mathbf{0 . 9 6 6 3}$ & 0.2890 & 0.5726 & $\mathbf{0 . 9 7 5 5 1}$ & 0.5568 & $\mathbf{0 . 9 0 4 3}$ & $\mathbf{0 . 9 3 2 6}$ \\
\cline { 2 - 10 } & $\mathrm{S}$ & -- & $7.2 \mathrm{E}-14$ & 0.1809 & 0.0043 & $2.6 \mathrm{E}-15$ & 0.0057 & $3.2 \mathrm{E}-09$ & $9.2 \mathrm{E}-11$ \\
\hline \multirow{3}{*}{ B1 } & $\mathrm{R}$ & $\mathbf{0 . 9 6 6 3}$ & 1 & 0.2996 & 0.6264 & $\mathbf{0 . 9 4 4 2 9}$ & 0.56064 & $\mathbf{0 . 9 6 1 3 7}$ & $\mathbf{0 . 9 4 9 3}$ \\
\cline { 2 - 10 } & $\mathrm{S}$ & $7.2 \mathrm{E}-14$ & -- & 0.1648 & 0.0013 & $1.3 \mathrm{E}-11$ & 0.0053 & $3.0 \mathrm{E}-13$ & $4.9 \mathrm{E}-12$ \\
\hline \multirow{2}{*}{ A2 } & $\mathrm{R}$ & 0.2890 & 0.2996 & 1 & 0.7804 & 0.2134 & 0.8909 & 0.2629 & 0.3310 \\
\cline { 2 - 10 } & $\mathrm{S}$ & 0.1809 & 0.1648 & -- & $1.1 \mathrm{E}-05$ & 0.3281 & $1.2 \mathrm{E}-08$ & 0.2255 & 0.1228 \\
\hline \multirow{2}{*}{ B2 } & $\mathrm{R}$ & 0.5726 & 0.6264 & 0.7804 & 1 & 0.5029 & 0.8016 & 0.5918 & 0.6777 \\
\cline { 2 - 10 } & $\mathrm{S}$ & 0.0043 & 0.0013 & $1.1 \mathrm{E}-05$ & -- & 0.0144 & $4.2 \mathrm{E}-06$ & 0.0029 & $3.8 \mathrm{E}-04$ \\
\hline \multirow{2}{*}{ C1 } & $\mathrm{R}$ & $\mathbf{0 . 9 7 5 5}$ & $\mathbf{0 . 9 4 4 2}$ & 0.2134 & 0.5029 & 1 & 0.4902 & 0.8618 & $\mathbf{0 . 9 0 4 9}$ \\
\cline { 2 - 10 } & $\mathrm{S}$ & $2.6 \mathrm{E}-15$ & $1 . \mathrm{E}-11$ & 0.3281 & 0.0144 & -- & 0.0175 & $1.2 \mathrm{E}-07$ & $3.0 \mathrm{E}-09$ \\
\hline \multirow{2}{*}{ C2 } & $\mathrm{R}$ & 0.5568 & 0.5606 & 0.8909 & 0.8016 & 0.4902 & 1 & 0.5376 & 0.6282 \\
\cline { 2 - 10 } & $\mathrm{S}$ & 0.0057 & 0.0059 & $1.2 \mathrm{E}-08$ & $4.2 \mathrm{E}-06$ & 0.0177 & -- & 0.0081 & 0.0013 \\
\hline \multirow{2}{*}{ D1 } & $\mathrm{R}$ & $\mathbf{0 . 9 0 4 3}$ & $\mathbf{0 . 9 6 1 3}$ & 0.2629 & 0.5918 & 0.8618 & 0.5376 & 1 & $\mathbf{0 . 9 2 4 3}$ \\
\cline { 2 - 9 } & $\mathrm{S}$ & $3.2 \mathrm{E}-09$ & $3.0 \mathrm{E}-13$ & 0.2255 & 0.00293 & $1.2 \mathrm{E}-07$ & 0.0081 & -- & $2.8 \mathrm{E}-10$ \\
\hline \multirow{2}{*}{ D2 } & $\mathrm{R}$ & $\mathbf{0 . 9 3 2 6}$ & $\mathbf{0 . 9 4 9 3}$ & 0.33101 & 0.67773 & $\mathbf{0 . 9 0 4 9 6}$ & 0.62812 & $\mathbf{0 . 9 2 4 7}$ & 1 \\
\cline { 2 - 9 } & $\mathrm{S}$ & $9.2 \mathrm{E}-11$ & $4.9 \mathrm{E}-12$ & 0.1228 & $3.8 \mathrm{E}-04$ & $3.0 \mathrm{E}-09$ & 0.0013 & $2.8 \mathrm{E}-10$ & -- \\
\hline
\end{tabular}

The metabolites responsible for statistical discrimination were P11 (luteolin 3'O-(4"O-acetyl) ß-D-glucuronide), P22 (carnosic acid), P15 (carnosol), P16 (quercetin), P9 (rosmarinic acid), and P19 (benthamic acid).

Table 3 presents the Pearson correlation factors $(R)$ and their statistical significance (S), considering the mean total concentrations of all twenty-three phytochemical found in rosemary accession groups. Significant correlations ( $R>0.90$ ) were noticed among "summer" accession groups A1-B1-C1-D1 but no significant correlations inside "spring" groups A2, B2 and C2. No correlations between the profiles of phytochemicals in spring season versus summer season in gypsum and semi-arid areas (e.g. A1 vs A2, B1 vs B2, C1 vsC2) were noticed, excepting the saline dune with significant positive correlations (D1 vs D2). 
HPLC-DAD-ESI'-MS PHYTOCHEMICAL PROFILES OF SEVERAL ROSMARINUS OFFICINALIS ACCESSIONS FROM SPAIN AS INFLUENCED BY DIFFERENT ENVIRONMENTAL

\section{Metabolic relevance of phytochemicals' profile and their stress- regulated pathways}

According to the qualitative and quantitative data, the specific biosynthetic pathways for phenolics and terpenoids in rosemary were affected by the environmental stress factors (water stress/salinity/altitude).

Mainly the water stress (soil aridity) during the dry summer season and the salt stress, to a lesser extent, were key factors that up-regulated the synthesis of phenolics, especially the flavonoids pathways and their glycosylation, for the protection of cell membranes against dryness. Water stress was signalised as the factor inducing significant changes in the metabolites profiles in this species [13] and salinity increased total amount of antioxidants in rosemary plants grown under increasing concentratiosn of $\mathrm{NaCl}$ [39].

The diterpene synthesis was also affected, especially by the oxidative degradation of carnosic acid to rosmanol and its derivatives, induced and amplified by dryness and salinity, in agreement with previous published data on rosemary [7,13]. Antioxidant properties of carnosic acid in in vitro sytems were used in food technology and medicine [40]. It has been recently establishing that oxidation of carnosic acid is an efficient ROS scavenger mechanism and fulfils an important antixodant role in this species in planta [26]. The oxidized metabolites of carnosic acid, such as carnosol, acid carnosol, rosmanol, and epirosmanol are also strong antioxidants. As such, carnosic acid oxidation is a "cascade-type process", generating different secondary antioxidants, and constitutes a very efficient anti-oxidant mechanism in labiates. To confirm the impact of environmental stress on phenolics and diterpene metabolism, a principal component analysis (PCA) was carried out (Fig. 3).

The PCA biplot shows the relationships and variance between the environmental factors (altitude, rainfall, temperature and soil humidity) and the concentrations of the nine major compounds presented in Table 2. The three main components with eigenvalues equal to or higher than 1 explain a significant cumulative variance of $86.46 \%$. The first component, that explain $64.77 \%$ of the variance is positively correlated with water availability (rainfall and soil humidity). The second component which explain an additional $15.50 \%$ is related to altitude. These findings are in agreement with previous observations [36] where positive correlations were found between total phenolics and flavonoids and water stress. It is therefore strongly supported the idea that the phenolics' synthesis is intensified by water stress and may contribute to the drought tolerance in $R$. officinalis, as it has been reported in many other plant species [41]. 


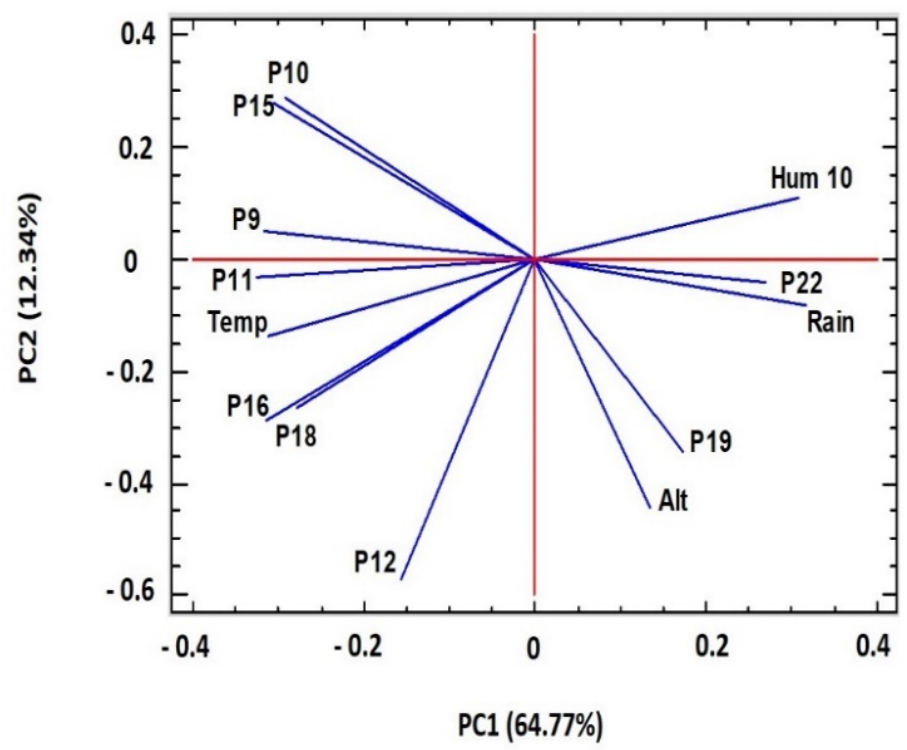

Figure 3. Biplot by the principal component analysis showing the relationships and variance between the environmental factors (altitude, rainfall, temperature and soil humidity) and the concentrations of the nine major compounds identified expressed as micrograms rutin/g dry leaf. For compound identification and quantification see Table 1.

\section{CONCLUSIONS}

Using an advanced methodology, HPLC-DAD-ESI+-MS, the phytochemical profiles of several Rosmarinus officinalis accessions from four different habitats in Spain, at two seasons (summer vs. spring), as influenced by different environmental stress (water stress and soil salinity), were established.

There were separated and quantified 23 molecules, nine being major: rosmarinic acid, two isomers of luteolin acetyl glucuronide, rosmanol, carnosol, quercetin, rosmadial, benthamic acid, carnosic acid. According to the qualitative and quantitative data, the specific biosynthetic pathways for these phenolics and terpenoids were affected by the environmental stress factors (water stress/salinity/altitude).

The diterpene derivatives and their oxidized metabolites were more sensitive than flavonoids to environmental stress and can be considered good biomarkers of water stress in wild $R$. officinalis grown in areas affected by the Mediterranean climate. By Cluster Analysis and Principal Component Analysis, the differences between the accession groups were determined, 
HPLC-DAD-ESI'-MS PHYTOCHEMICAL PROFILES OF SEVERAL ROSMARINUS OFFICINALIS ACCESSIONS FROM SPAIN AS INFLUENCED BY DIFFERENT ENVIRONMENTAL

being dependent on the environmental conditions. These data underline the key role of carnosic acid and its up-regulated biosynthesis by water and its degradation to oxidized derivatives, as an adaptation to water stress.

\section{EXPERIMENTAL SECTION}

\section{Environmental conditions and sample harvesting}

Rosemary leaves were harvested from different areas in the province of Valencia (Spain) growing in distinct environmental growth conditions: a plot in a sea sand dune; a plot in a semiarid area on limestone substrate at $200 \mathrm{~m}$ altitude, and two plots on a hill in a gypsum area at an altitude of about $700 \mathrm{~m}$. To assess the climatic conditions from each area, data on mean temperatures from the previous month and accumulated rainfall were collected on a daily basis from the nearest agroclimatological stations, located in Benifaió (less than $6 \mathrm{~km}$ from the dune zone), Bétera (10 km from the semiarid zone) and Chulilla (18 $\mathrm{km}$ from the gypsum area). Soil water content was monitored through several sensors for soil moisture installed to $10 \mathrm{~cm}$ depth, connected to data loggers. For a more extensive description of the soil and climatic characteristics of the experimental zones, see [36].

The dune area is a stressful environment given its proximity to the sea, but plants were also affected by a constant water stress due to the low water retention by sand and the moderately saline shallow water table. In the semiarid zone, the plants were grown on a thin soil over a stony bedrock, the main stress factor being the water deficit in the dry season. In the gypsum area, it was a combination of salt and water stress (since gypsum soils are found always under arid climatic conditions). In this area, different environmental conditions were found at the top (with low gypsum, drier soil) and bottom areas of a hill (more gypsum, more humid, even during the summer season). In order to investigate the effect of different levels of water stress, the samples were collected from the same plants, during two seasons: summer, after a month without rainfall, and spring, after a rainy period.

Young shoots of flowering rosemary plants were sampled separately from five individuals from each locality, cooled on ice and transported to the laboratory, where leaves were separated from branches and dried in an oven at $45^{\circ} \mathrm{C}$ for $72 \mathrm{~h}$ until constant weight. The harvested rosemary samples are indicated in Table 4. 
Table 4. The rosemary accessions coding according to habitat and sampling

season. Temperature values and accumulated rainfall were recorded by the nearest agro-climatological stations and correspond to the month before sampling date. Soil humidity was measured by electronic sensors installed at $10 \mathrm{~cm}$ depth.

\begin{tabular}{|c|c|c|c|c|c|c|}
\hline Habitat & $\begin{array}{l}\text { Code } \\
(\mathrm{m})\end{array}$ & $\begin{array}{l}\text { Sampling } \\
\text { date }\end{array}$ & $\begin{array}{c}\text { Number of } \\
\text { samples }\end{array}$ & $\begin{array}{c}\text { Mean } \mathrm{T} \\
\quad\left({ }^{\circ} \mathrm{C}\right)\end{array}$ & $\begin{array}{c}\text { Cumulated } \\
\text { rainfall } \\
(\mathrm{mm})\end{array}$ & $\begin{array}{c}\text { Soil } \\
\text { humidity } \\
\mathrm{cm}^{3} / \mathrm{cm}^{3}\end{array}$ \\
\hline \multirow[t]{2}{*}{ Gypsum Top 710 m } & A1 & Summer (I) & 5 & 24.8 & 7 & 0.111 \\
\hline & A2 & Spring (II) & 5 & 12.0 & 113 & 0.194 \\
\hline \multirow{2}{*}{$\begin{array}{l}\text { Gypsum Bottom } \\
690 \mathrm{~m}\end{array}$} & B1 & Summer (I) & 4 & 24.8 & 7 & 0.139 \\
\hline & B2 & Spring (II) & 4 & 12.0 & 113 & 0.258 \\
\hline \multirow{2}{*}{$\begin{array}{l}\text { Semiarid } \\
220 \mathrm{~m}\end{array}$} & C1 & Summer(I) & 4 & 25.9 & 3 & 0.008 \\
\hline & $\mathrm{C} 2$ & Spring (II) & 5 & 14.1 & 35 & 0.242 \\
\hline \multirow[t]{2}{*}{ Sand sea dune } & D1 & Summer (I) & 4 & 21,0 & 1 & 0.073 \\
\hline & D2 & Spring (II & 5 & 13.5 & 50 & 0.138 \\
\hline
\end{tabular}

\section{Extraction protocols}

Aliquots of rosemary dried leaves $(2 \mathrm{~g})$ were mixed with aq. methanol $95 \%(20 \mathrm{ml})$ containing $1 \% \mathrm{HCl}$ (aq.), stirred and kept in an ultrasonic bath (XUB5 model, at operating frequency of $32 \mathrm{KHz}$ and power supply of $100 \mathrm{~W}$ ), for $24 \mathrm{~h}$ at $25^{\circ} \mathrm{C}$. After centrifugation (2000 rpm), the supernatant was filtered through a $0.25-\mu \mathrm{m}$ nylon filter. All the extractions were done in duplicate for each sample.

\section{UV-VIS spectrometry}

As a preliminary evaluation of extracts, the UV absorption profiles were determined by recording the spectra from 200 to $400 \mathrm{~nm}$ (using a UV/Vis Lambda 25 Perkin Elmer spectrophotometer), looking to the peaks at 280 and $340 \mathrm{~nm}$, as markers of the phenolic acid and flavonoids, respectively.

\section{HPLC-DAD and LC-ESI+-MS analysis}

A simultaneous evaluation (qualitative and quantitative) of phytochemicals was done using an Agilent 1200 HPLC Series system (Agilent Technologies, Santa Clara, CA. USA). The extract components were separated in a Zorbax Eclipse XDBC18 column (4.6 X $150 \mathrm{~mm} ; 5 \mu \mathrm{m}$ particle), at $25^{\circ} \mathrm{C}$. The mobile phase consisted of a mixture of water:acetonitrile:acetic acid $(99: 0.9: 0.1, \mathrm{v} / \mathrm{v} / \mathrm{v})($ solvent $A)$ and acetonitrile:acetic acid $(99.9: 0.1, \mathrm{v} / \mathrm{v})$ (solvent B). The linear gradient for solvent B was as follows: $0-2$ min.: $5 \%$ B, 
2- $18 \mathrm{~min}$. (from 5 to $40 \% \mathrm{~B}$ ), 18 - $40 \mathrm{~min}$ (from 40 to $90 \%$ B) $20-24 \mathrm{~min}$ (isocratic $90 \% \mathrm{~B}$ ), $24-27.5 \mathrm{~min}$. (from 90 to $5 \% \mathrm{~B}$ ). The flow rate was $0.5 \mathrm{~mL} / \mathrm{min}$ and the injection volume of the sample dissolved in methanol was $5 \mu \mathrm{L}$. Before injecting, all the samples were filtered through a PTFE filter $(13 \mathrm{~mm}$ i.d., $0.22 \mu \mathrm{m}$ ). The HPLC system was equipped with a diode array (DADG1315D) detection at specific wavelengths (280 and $340 \mathrm{~nm}$ ). The system was coupled online with a single quadrupole mass spectrometer (MS) (Agilent Technologies 6110 system, Santa Clara, USA), in the ESI ${ }^{+}$mode. The MS settings were: dry gas $\mathrm{N}_{2}$ at a flow rate of $8 \mathrm{~L} / \mathrm{min}$; drying temperature at $350^{\circ} \mathrm{C}$, nebulizer pressure at $65 \mathrm{psi}$, capillary voltage of $3000 \mathrm{~V}$, scan range of $\mathrm{m} / \mathrm{z}$ from 150 to 1000 .

The HPLC-DAD analysis was applied for the optimization of the phytochemicals separation and for the quantitative evaluation, based on chromatograms recorded at $340 \mathrm{~nm}$.

For an accurate identification of the metabolites, the HPLC-DAD separation protocol was optimized using pure standards of phenolic acids (p-coumaric, caffeic and syringic acid) absorbing at $280 \mathrm{~nm}$, and flavonoids (quercetin and rutin), carnosic acid and betulinic acid of 95-99\% purity (purchased from Sigma Aldrich), at $340 \mathrm{~nm}$. All pure standards were dissolved in methanol and injected individually and as a mixture in the HPLC column and their specific retention times $\left(t_{R}\right)$ and UV absorption spectra were recorded.

For the quantification of metabolites, the optimized HPLC-DAD separation protocol was applied using pure rutin (quercetin 3-O-rutinoside) standard to build a calibration curve, based on five different concentrations $(10,5,2.5,1.25$ and 0.625 micrograms rutin $/ \mathrm{mL})$. The calibration curve was represented by a regression equation $y=32.846+273.7 ; R^{2}=0.9983$ used to calculate the concentrations of metabolites separated by HPLC-DAD (expressed as micrograms rutin equivalents/ gram of dry sample).

The LC-ESI ${ }^{+}-\mathrm{MS}$ analyses aimed to fingerprint and identify the metabolites based on their $\mathrm{m} / \mathrm{z}$ values and fragmentation features, compared with literature reports and databases (Phenol Explorer, KEGG) finalized by tentative identification consistent with published data.

\section{Statistical Analysis}

The qualitative data derived from LC-ESI+-MS data were processed by non-targeted statistical analysis (Cluster Analysis and Principal Component Analysis), to discriminate the profile differences between the sampling groups depending on the environmental conditions. The mean values of identified compounds were compared by the Pearson correlation test, the significance of differences being established at 3E-9. 
MONICA BOSCAIU, OSCAR VICENTE, INMACULADA BAUTISTA,

FLORICUTA RANGA, CARMEN SOCACIU

\section{ACKNOWLEDGMENTS}

We acknowledge the contribution of our collaborators from the Applied Biotechnology Centre BIODIATECH-Proplanta SRL, as well the funding from the Spanish Ministry of Science and Innovation (Project CGL200800438/BOS) and the contribution of European Regional Development Fund.

\section{REFERENCES}

1. S. Moreno; T. Scheyer; C.S. Romano; A. Vojnov; Free Rad. Res. 2006, 40, 223231.

2. B. Bozin; N.Mimica-Dukic; I. Samojlik; E. Jovin; J. Agric. Food. Chem. 2007, 55, 7879-7885.

3. E. Issabeagloo; P. Kermanizadeh; M. Taghizadieh; R. Forugh; Afr. J. Microbiol. Res. 2012, 6, 5039-5042.

4. T. Kayashima; K. Matsubara; K.Ayashima; K. Matsubara; Biosci. Biotechnol. Biochem. 2012, 76, 115-119.

5. S. Habtemariam; Evid. Based Complement. Alternat. Med. 2016, 2680409.

6. G. Zgórka; K. Glowniak; J. Pharm. Biomed. Anal. 2001, 26, 79-87.

7. J.C. Luis; C.B. Johnson; Span. J. Agric. Res. 2005, 3, 106-112.

8. European Medicines Agency. Community herbal monograph on Rosmarinus officinalis L. aetheroleum. 2010, Available from: http//www.ema.europa.eu/ WC500101493.pdf

9. I. Cocan; E. Alexa; C. Danciu; I. Radulov; A. Galuscan; D. Obistioiu; A.A. Morvay; R.M. Sumalan; M.A. Poiana; G. Pop; C.A. Dehelean; Exp. Ther. Med. 2018, 15, 1863-1870.

10. M.B.Hossain; D.K. Rai; N.P. Brunton; D.A.B. Martin; C. Barry-Ryan; J. Agric. Food. Chem. 2010, 58, 10576-10581.

11. K. Hcini; J.A. Sotomayor; M.J. Jordan; S. Bouzid; Asian J. Chem. part B 2013, 25, 9299-9301.

12. A. Vallverdú Queralt; J. Regueiro; M. Martìnez Huélamo; J.F. Rinaldi Alvarenga;

L. Leal; N. Lamuela Raventos; Food Chem. 2014, 154, 299-307.

13. S. Munne Bosch; L. Alegre; Planta 2000, 210, 925-931.

14. M.J. Del Baño; J. Lorente; J. Castillo; O. Benavente García; M.P.Marín; J.A. Del Río; A. Ortuño; I. Ibarra; J. Agric. Food Chem. 2004; 52, 4987-4992.

15. C. Bicchi; A. Binello; P. Rubiolo; Phytochem Anal. 2010, 11, 236-242.

16. P. Mena; M. Cirlini; M. Tassotti; K.A. Herrlinger; C. Dall'Asta; D. Del Rio; Molecules 2016, 21, 1576-1587; 
HPLC-DAD-ESI'-MS PHYTOCHEMICAL PROFILES OF SEVERAL ROSMARINUS OFFICINALIS ACCESSIONS FROM SPAIN AS INFLUENCED BY DIFFERENT ENVIRONMENTAL

17. M. Herrero; M. Plaza; A. Cifuentes; E. Ibañez; J. Chromatogr. 2010, 1217, 2512-2520.

18. I. Borrás Linares; Z. Stojanović; R. Quirantes Piné; D. Arráez Román; J. Švarc Gajić; A. Fernández Gutiérrez; A. Segura Carretero; Int. J. Mol. Sci. 2014, 15, 20585-20606.

19. M. Mulinacci; M. Innocenti; M. Bellumori; C. Giaccherini; V. Martini; M. Michelozzi; Talanta, 2011, 85, 167-176.

20. C.R.L. Wellwood; R.A. Cole; J. Agric. Food Chem. 2004, 52, 6101-6107.

21. L. Almela; B. Sánchez Muñoz; J.A. Fernández López; M.J. Roca; V. Rabe; J. Chromatogr. 2006, 1120, 221-229.

22. M.J. Jordan; V. Lax; M.C. Rota; S. Loran; J.A. Sotomayor; Ind. Crops Prod. 2013, 48, 144-152.

23. D. Meziane Assami; V. Tomao; K. Ruiz; B.Y. Meklati; F. Chemat; Food Anal. Meth. 2013, 6, 282-288.

24. M.H. Mehrizi; H. Shariatmadari; A.H. Khoshgoftarmanesh; F. Dehghani; J. Agr. Sci. Technol.-Iran 2012, 14, 205-212.

25. T. Tounekti; A.M. Vadel; M. Ennajeh; H. Khemira; S. Munné-Bosch; J. Plant Nutr. Soil Sci. 2011, 174, 504-514.

26. M. Loussouarn; A. Krieger-Liszkay; L. Svilar; A. Bily; S. Birti; M. Havaux; Plant Physiol. 2017, 175, 1381-1394

27. V. Papageorgiou; C. Gardeli; A. Mallouchos; M. Papaioannou; M. Komaitis; J. Agric. Food Chem. 2008, 56, 7254-7264.

28. A. Caverzan; A. Casassola; S. Patussi Brammer; In Abiotic and biotic stress in plants. Recent advances and future perspectives. 2016. Arun Shanker, IntechOpen, pp.463-481

29. A. Fini; C. Brunetti; M. Di Ferdinando; F. Ferrini; M. Tattini; Plant Signal. Behav. 2011, 6, 709-711.

30. K.S. Gould; C. Lister; In Andersen ØM, Marham KR (eds) Flavonoids, chemistry, biochemistry and application, Boca Raton, FL: CRC Press, 2006, 397-442.

31. D. Treutter; Environ. Chem. Lett. 2006, 4, 147-157.

32. B. Winkel-Shirley; Curr. Opin. Plant Biol. 2002, 5, 218-223.

33. M. Di Ferdinando; C. Brunetti; A. Fini; M. Tattini; In Ahmad P, Prasad MNV (eds) Abiotic stress responses in plants: metabolism, productivity and sustainability, New York: Springer, 2012, 159-179.

34. J. Mierziak; K. Kostyn; A. Kulma; Molecules 2014, 19, 16240-16265;

35. J. Grassmann; Vitam. Horm. 2005, 72, 505-535.

36. I. Bautista; M. Boscaiu; A. Lidón; J.V. Llinares; C. Lull; M.P. Donat; O. Mayoral; O. Vicente; Acta Physiol. Plant. 2016, 38, 9-16.

37. Y. Zhang; J.P. Smuts; E. Dodbiba; R. Rangarajan; J.C. Lang; D-W. Armstrong; J. Agric.Food Chem. 2012, 60, 9305-9314.

38. N. Bai; K. He; M. Roller; C. Lai; X.Shao; M. Pan; C.T.Ho; J. Agric. Food Chem. 2010, 58, 5363-5367. 
MONICA BOSCAIU, OSCAR VICENTE, INMACULADA BAUTISTA,

FLORICUTA RANGA, CARMEN SOCACIU

39. K. Kiarostami; R. Mohseni; S. Azra; J. Stress Physiol. Biochem. 2010, 6, 114122.

40. S. Birtić; P. Dussort; F.X. Pierre; A.C. Bily; M. Roller; Phytochemistry 2015, 115, 9-19.

41. L. Yang; K.S. Wen; X. Ruan; Y.-X. Zhao; F. Wei; Q.Wang; Molecules 2018, 23, 762-769. 